\title{
Characterization of HCHs and DDTs in urban dustfall and prediction of soil burden in a metropolis-Beijing, China
}

\author{
Hangxin Cheng ${ }^{\mathrm{a}, *}$, Lingling Ma ${ }^{\mathrm{b}, *}$, Chuandong Zhao ${ }^{\mathrm{a}}$, Xinghong $\mathrm{Li}^{\mathrm{c}}$, Xiaofei Wang ${ }^{\mathrm{c}}$, \\ Yinghan Liu ${ }^{a}$, Ke Yang ${ }^{a}$ \\ a Institute of Geophysical and Geochemical Exploration, Chinese Academy of Geological Sciences, Langfang 065000, China \\ ${ }^{\mathrm{b}}$ Key Laboratory of Nuclear Analytical Techniques, Institute of High Energy Physics, Chinese Academy of Sciences, Beijing 100049, China \\ ' State Key Laboratory of Environmental Chemistry and Ecotoxicology, Research Center for Eco-Environmental Sciences, Chinese Academy of Sciences, Beijing 100085, China
}

\section{A R T I C L E I N F O}

\section{Article history:}

Received 11 February 2011

Received in revised form 11 July 2011

Accepted 29 July 2011

Available online 14 September 2011

\section{Keywords:}

$\mathrm{HCHs}$

DDTs

Dustfall

Flux

Fugacity

\begin{abstract}
A B S T R A C T
The concentrations, spatial distribution and compositional patterns of extensively used hexachlorocyclohexanes (HCHs) and dichlorodiphenyltrichloroethanes (DDTs) in urban dustfall in a metropolis-Beijing are presented in this paper. The potential sources are discussed and soil burdens are predicted based on the fluxes. The hotspots in commercial areas are identified by spatial distribution maps and the fractional value isomers indicates that dustfall in urban Beijing are affected by both current and historical usage of DDTs. It is worth noticing that there is possible application "dicofol-type of DDTs" in Beijing. The measured atmospheric deposition flux is $1.14 \times 10^{5} \mathrm{ng} \mathrm{h}^{-1} \mathrm{~m}^{-2}$ for HCHs and $1.47 \times 10^{5} \mathrm{ng} \mathrm{h}^{-1} \mathrm{~m}^{-2}$ for DDTs, respectively. However, when compared with atmospheric deposition flux, the volatilization flux estimated from concentrations in soils by fugacity model is significantly lower for HCHs (2.41 $\mathrm{ng} \mathrm{h}^{-1} \mathrm{~m}^{-2}$ ) and DDTs $\left(0.07 \mathrm{ng} \mathrm{h}^{-1} \mathrm{~m}^{-2}\right.$ ). The net atmospheric flux to the soil suggests that the levels of HCHs and DDTs in soil are dominated by atmospheric deposition and the urban soil in Beijing would be a sink for HCHs and DDTs in the long term.
\end{abstract}

Crown Copyright $\odot 2011$ Published by Elsevier Ltd. All rights reserved.

\section{Introduction}

Organochlorine pesticides (OCPs) are receiving continuous concerns due to the persistently negative impacts on the environment and human health (Li et al., 2009; Liu et al., 2009; Tao et al., 2009; Roosens et al., 2010). China is known for intensive production and consumption of hexachlorocyclohexane isomers (HCHs) and dichlorodiphenyltrichloroethane with metabolites (DDTs) for more than three decades (MCI, 1992). Although the usage of DDTs and technical HCHs was banned by the government in 1983, technical DDTs is still being produced and used for non-agricultural purposes such as malaria control (Li et al., 2001). The quality of the urban environment is of growing concern as its human population continues to dramatically increase. Beijing, the capital with a population up to 13 million, is the second largest city in northern China. The rapid industrialization during the last decades had resulted in a lot of environmental problems. There was a long history of heavy production/usage of HCHs and DDTs in Beijing (Li et al., 1998). For the valid use of urban land and the safety of public health, a systematic project was carried out in 2000 to

\footnotetext{
* Corresponding authors. Tel.: +86 316 2267630; fax: +86 3162014156.

E-mail addresses: hangxin@vip.sina.com (H. Cheng), malingling@ihep.ac.cn (L. Ma).
}

assess the soil contamination in Beijing. The high concentrations of HCHs and DDTs together with other semi-volatile persistent organic pollutants were observed (Ma et al., 2005; Zhu et al., 2005; Li et al., 2006). Contaminated soil could still continue to be a source of current atmospheric contamination and result in ongoing exposure for the public health. As a continuous study of the previous "2000 project", atmospheric particulate matter (PM) was characterized in urban city in 2005 and Beijing was categorized as a city that is highly contaminated with OCPs (Wang et al., 2008).

Atmospheric deposition has been of a considerable environmental interest due to its important role in OCPs transportation (Pozo et al., 2006). A few recent studies further revealed the increasing concentrations of HCHs and DDTs in various environmental media in Beijing (Xu et al., 2004, 2005, 2009; Li et al., 2009). The concentrations of OCPs in atmosphere decreased with boundary layer height, which indicated the potential of Beijing as a local source of OCPs (Li et al., 2009). The observed high levels of OCPs in the atmosphere may be due to the ongoing usage as well as emission of old residues from surface soil, which have a huge retention capacity of organic pollutants and is considered as the ultimate sink for OCPs (MCI, 1992; Wong et al., 2008). Airborne dust may be delivered to surfaces by bulk deposition and has been a notable atmospheric feature of China since ancient times (Derbyshire et al., 1998). As an important source of urban 
atmospheric particulate matter and house dust, dustfall $(d>10 \mu \mathrm{m})$ is scavenged mainly by gravity and thus tends to reflect potentially non-point sources near the sampling sites ( $\mathrm{Wu}$ et al., 2005). As the carrier of pollutants, dustfall not only affects urban air quality but also directly threatens public health. However, limited reports on OCPs are currently available, despite the fact that atmospheric pesticide pollution has been well documented worldwide. Since precipitation is rare in Beijing, the dry deposition of airborne OCPs has a high likelihood of being the predominant mode of atmospheric OCPs input into underlying surfaces.

To get an understanding of atmospheric OCPs level and its contribution to the soil burden, bulk deposition (dry and wet deposition together) were collected in a municipal scale during 1 year period by passive sampling method in this study. HCHs and DDTs will be characterized and the hot-spots will be recognized according to the spatial maps. Furthermore, modeling will be conducted on the soil burdens in Beijing based on the fluxes and reported levels of pesticide on surface soil.

\section{Materials and methods}

\subsection{Materials and reagents}

A mixed stock standard solution was obtained from National Research Center for Certified Reference Materials of China at a concentration of $100 \mathrm{mg} \mathrm{L}^{-1}$ and further diluted to obtain the desired concentration. The surrogate of 2,4,5,6-tetrachloromxylene (TCMX) was bought from Supelco (Bellfonte, USA). Florisil (Dikma Co. USA) was activated at $600^{\circ} \mathrm{C}$ for $6 \mathrm{~h}$ and then at $130{ }^{\circ} \mathrm{C}$ for $16 \mathrm{~h}$. All solvents were of analytical grade and redistilled in all-glass system prior to use.

\subsection{Dustfall sampling}

The Beijing city occupies a surface area of $16807 \mathrm{~km}^{2}$, with $748 \mathrm{~km}^{2}$ classified as urban area. Twenty flat bottom ceramic buckets ( $32 \mathrm{~cm}$ i.d., height of $40 \mathrm{~cm}$ ) for collecting bulk deposition on 6-10 m high stands situated throughout the urban area of the city from December 2005 to November 2006. The buckets were thoroughly washed with distilled water and acetone/hexane before setting. Dustfall particles were wipes off from the bottom of buckets with a brush and then washed twice with distilled water and freeze-drying. The dustfall samples were weighted and then stored in glass jars and kept in a refrigerator at $-18{ }^{\circ} \mathrm{C}$ before analysis. The climate of the country as a whole is dominated by temperate semi-wetness monsoons, and the annual temperature during the sampling period was from $-4{ }^{\circ} \mathrm{C}$ to $27^{\circ} \mathrm{C}$ with a mean value of $13^{\circ} \mathrm{C}$. The study area was divided into regular grids of $7 \mathrm{~km}^{2} \times 7 \mathrm{~km}^{2}$ based on approximately equal longitude and latitude. The detailed sampling locations are shown in Fig. 1. The sample numbered 19 was lost due to the housebreaking and no data was shown with regards to this site. Five different functional zones (industrial: sample of 3, 4, 6, 10,11, 15 and 20; commercial area: sample of 2, 8, 9 and 12; residential area: sample of 1,7 and 14; farm: sample of 5 and 18; park: sample of 13 and 17) were divided according to the surrounding environment of the sampling sites. The sample of 16 was collected in a desertification area beside Yongding River.

\subsection{Sample extraction and cleanup}

The cleanup and analytical procedures were carried out according the previous reports (Li et al., 2006; Wang et al., 2008). Briefly, after $1 \mathrm{~mL}$ of TCMX added, the dustfall was ultrasonically extracted in $30 \mathrm{~mL}$ acetone/hexane (1/1) thrice and centrifuged for separation. Then the solvent was rotary evaporated and then reduced to $1 \mathrm{~mL}$ under the gentle stream of nitrogen. The concentrated extract was further cleaned up with a Florisil column $(30 \mathrm{~cm} \times$ $10 \mathrm{~mm}$ i.d.) packed with $5 \mathrm{~g}$ of florisil (in hexane). It was eluted with $40 \mathrm{~mL}$ of hexane/ethyl ether $(7 / 1, v / \mathrm{v})$. The solvent was reduced to $0.1 \mathrm{~mL}$ under a gentle nitrogen stream before analysis.

\subsection{Instrumental analysis}

The measurement was performed on a 6890 gas chromatograph (GC, Agilent J\&W Co., USA) coupled to an electron capture detector (ECD) with a fused silica capillary $(30 \mathrm{~m} \times 0.25 \mathrm{~mm}$ i.d.) coated with a $0.25 \mu \mathrm{m}$ thick film of DB5 column (5\% phenylmethylpolysiloxane, Agilent J\&W Co., USA). Inlet and detector temperature were $225^{\circ} \mathrm{C}$ and $310^{\circ} \mathrm{C}$, respectively. The oven temperature program was as follows: initial temperature $100^{\circ} \mathrm{C}$ held for $2 \mathrm{~min}$, increased to $160{ }^{\circ} \mathrm{C}$ at $10^{\circ} \mathrm{C} \mathrm{min}^{-1}$, then to $230{ }^{\circ} \mathrm{C}$ at $4^{\circ} \mathrm{C} \mathrm{min}{ }^{-1}$ for $5 \mathrm{~min}$, and to $280^{\circ} \mathrm{C}$ at $10^{\circ} \mathrm{C} \mathrm{min}^{-1}$, then held for 10 min. Identification of the compounds was based on the retention time with corresponding standards and confirmed on a GC coupled to a 5973 mass selective detector (Agilent J\&W Co., USA). The inlet and detector temperature together with the temperature program were the same as those for the GC-ECD.

The recoveries were in the range of $75-115 \%$, and relative standard deviation $(n=5)$ was less than $10 \%$. The recoveries of

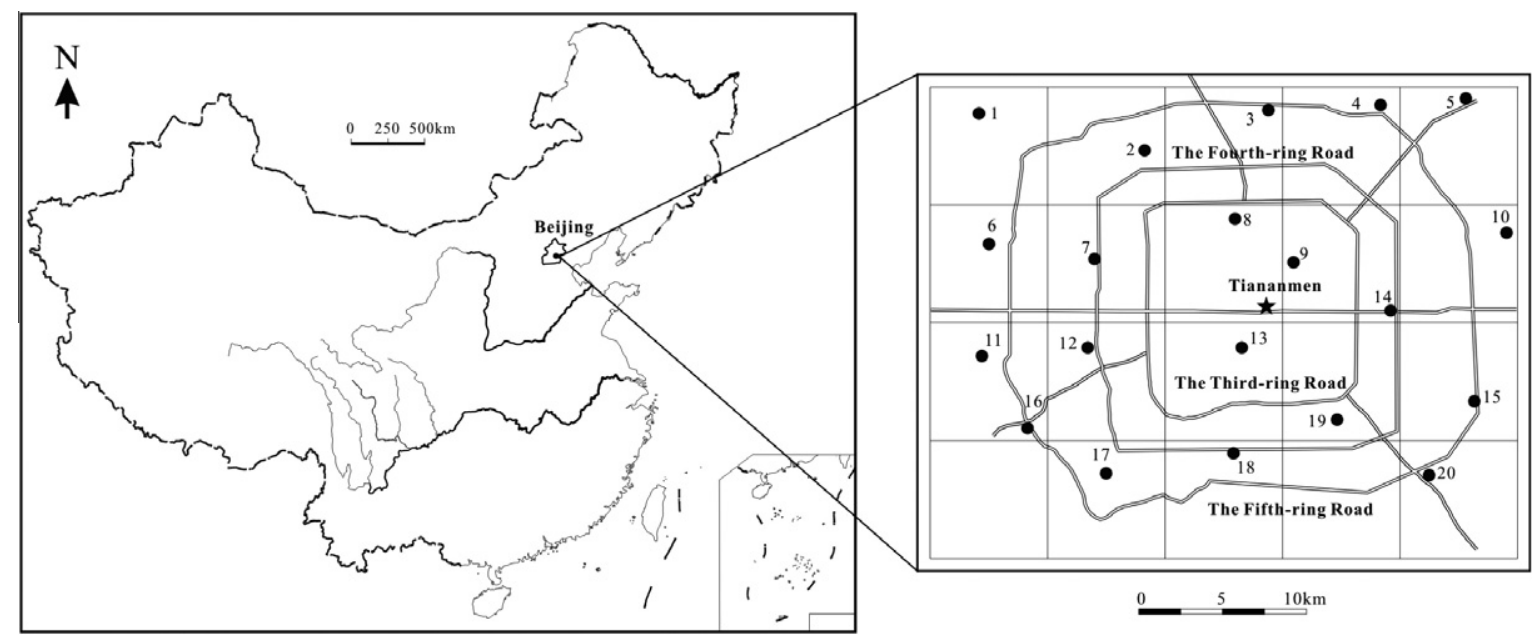

Fig. 1. Map of sampling site of urban dustfall in urban Beijing. 
surrogate spiked in bland, matrix, samples were between $84 \%$ and $109 \%$. The limits of detection (LODs), as three times response of signal-to-noise in matrix blanks $(n=5)$, ranged from $0.05 \mathrm{ng} \mathrm{g}^{-1}$ for $\alpha-\mathrm{HCH}$ to $0.15 \mathrm{ng} \mathrm{g}^{-1}$ for $\mathrm{p}, \mathrm{p}^{\prime}-\mathrm{DDT}$.

\subsection{Data analysis}

A global position system was employed to precisely record each location. Principal component analysis (PCA) was performed with SPSS 13.0 for Windows (SPSS Inc., Chicago, IL). Surfer (Version 8.0 , Golden software, CO. USA) was used to draw the spatial distribution maps.

\section{Results and discussion}

\subsection{Levels and spatial distribution}

The amount of dustfall varied from $9.00 \mathrm{~g}$ to $62.00 \mathrm{~g}$ with a median of $21.30 \mathrm{~g}$ in this study. Despite the restricted usage, $\mathrm{HCHs}$ and DDTs were still in detectable levels in the dustfall in urban Beijing. The maximum, 90th, 75th, 50th (median), 25th, and 10th percentiles and minimum of HCHs and DDTs in dustfall are shown in Fig. 2. A much wider ranges of $\sum \mathrm{HCHs}$ (sum of $\alpha-$, $\beta-, \delta-, \gamma-\mathrm{HCH}$ ) and $\sum$ DDTs (sum of p, $\mathrm{p}^{\prime}$-DDT, dichlorodiphenyldichloroethane ( $\left.\mathrm{p}, \mathrm{p}^{\prime}-\mathrm{DDD}\right)$, dichlorodiphenyldichloroethylene ( $\mathrm{p}, \mathrm{p}^{\prime}-$ $\mathrm{DDE})$ and $\mathrm{o}, \mathrm{p}^{\prime}$-DDT) were found with the coefficient of variation of 95.14 and 104.00 , respectively. $\sum$ DDTs (1.75-63.29 $\mathrm{ng} \mathrm{g}^{-1}$ with a median of $9.46 \mathrm{ng} \mathrm{g}^{-1}$ ) was higher than $\sum \mathrm{HCHs}$ (1.80-
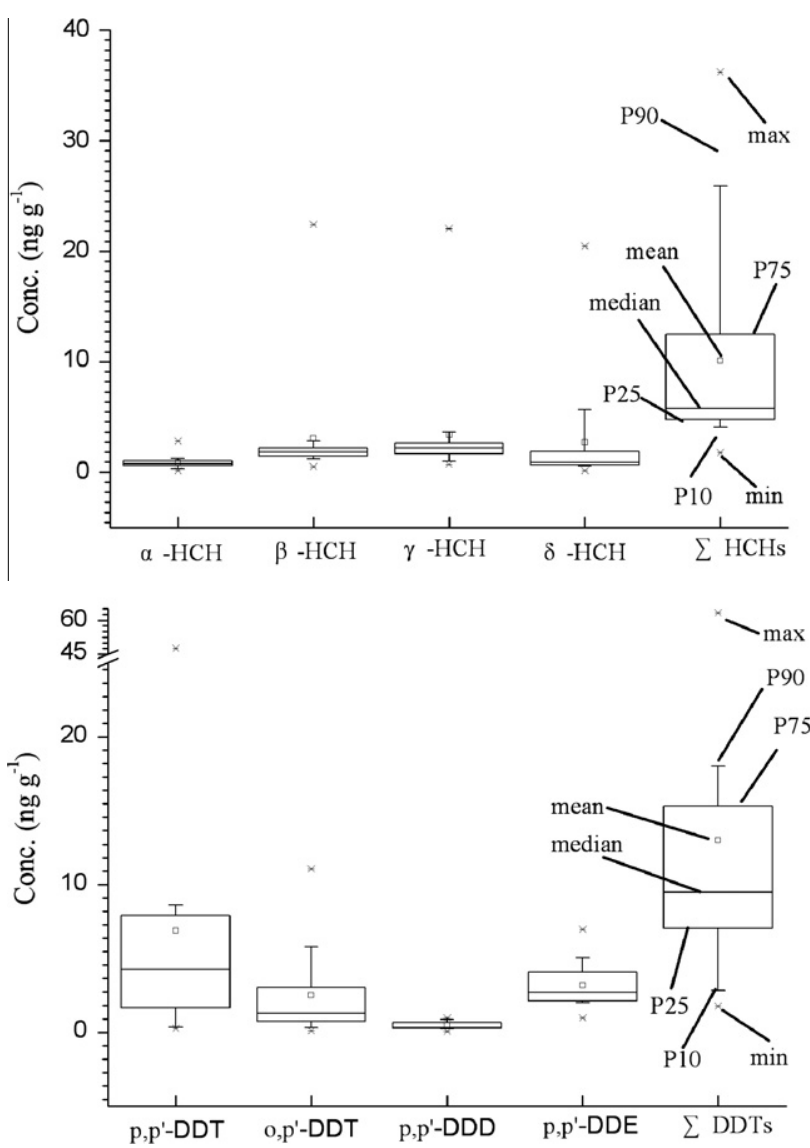

Fig. 2. Concentration of HCHs and DDTs in dustfall samples $\left(\mathrm{ng} \mathrm{g}^{-1}\right)$. The values of maximum, the 90th, 75th, 50th (median), 25th, and 10th percentiles, and minimum are illustrated by box-whisker symbols and the arithmetic means are present as “ $\square$ ".
$36.19 \mathrm{ng} \mathrm{g}^{-1}$ with a median of $5.77 \mathrm{ng} \mathrm{g}^{-1}$ ). The average concentration of $\sum \mathrm{HCHs}\left(6.87 \mathrm{ng} \mathrm{g}^{-1} \pm 10.62 \mathrm{ng} \mathrm{g}^{-1}\right)$ and $\sum$ DDTs (12.99 $\mathrm{ng} \mathrm{g}^{-1} \pm 13.51 \mathrm{ng} \mathrm{g}^{-1}$ ) were obviously lower than those in Tianjin, a large industrial city $120 \mathrm{~km}$ southeast of Beijing, whereas the average concentrations were $519.00 \mathrm{ng} \mathrm{g}^{-1}$ for $\sum \mathrm{HCHs}$ and $266.00 \mathrm{ng} \mathrm{g}^{-1}$ for $\sum$ DDTs, respectively (Wu et al., 2005).

The spatial distributions of HCHs and DDTs are shown in Fig. 3 by counter plots. The hotspots (sites 8 and 9) were located in the northern commercial center around the 3rd Ring Road and the 4th Ring Road for both HCHs and DDTs. For HCHs, another hotspot (site 20) was in the southeast city, which was consistent with the previous finding that the southeast city was highly polluted by OCPs in both topsoil and particulate matter (Li et al., 2006; Wang et al., 2008). Since dustfall would reflect the potential non-point sources nearby, the finding indicates that there are possible sources of OCPs in the commercial area. In order to probe the clue of sources, $\sum \mathrm{HCHs}$ and $\sum$ DDTs in five functional zones are checked. The levels of HCHs and DDTs were comparable in four zones except for the park with a much higher $\sum$ DDTs than $\sum \mathrm{HCHs}$. The average concentration of OCPs was in the order of commercial (23.18 $\mathrm{ng} \mathrm{g}^{-1}$ for $\mathrm{HCHs;} 27.76 \mathrm{ng} \mathrm{g}^{-1}$ ) $>$ park (8.97 $\mathrm{ng} \mathrm{g}^{-1}$ for HCHs; $20.88 \mathrm{ng} \mathrm{g}^{-1}$ for DDTs) $>$ industrial center $\left(8.05 \mathrm{ng} \mathrm{g}^{-1}\right.$ for HCHs; $10.56 \mathrm{ng} \mathrm{g}^{-1}$ for DDTs) $>$ farm $\left(9.41 \mathrm{ng} \mathrm{g}^{-1}\right.$ for HCHs; $8.76 \mathrm{ng} \mathrm{g}^{-1}$ for DDTs) $>$ residential area $\left(4.94 \mathrm{ng} \mathrm{g}^{-1}\right.$ for HCHs; $3.72 \mathrm{ng} \mathrm{g}^{-1}$ for DDTs). The results indicate the reliability of layout for residential areas in Beijing. However, the management of commercial areas and park should be strengthened for protecting public health.

\subsection{Composition of HCHs and DDTs}

Principal component analysis (PCA) was conducted and is provided by Table 1 . Three factors were extracted and accounted for 83.94\%. The first principal component explained $51.55 \%$ of total variance, was highly associated with $\alpha-\mathrm{HCH}, \beta-\mathrm{HCH}, \mathrm{p}, \mathrm{p}^{\prime}$-DDT, $0, \mathrm{p}^{\prime}$-DDT and p,p'-DDD. $\gamma-\mathrm{HCH}$ and $\delta$-HCH were related to the second component, indicating their similar origin. The third component explained $14.10 \%$ of the variance and with only $\mathrm{p}, \mathrm{p}^{\prime}$-DDE was significantly loaded on. The composition patterns are deserved to be discussed separately in order to get more information.

\subsection{1. $\mathrm{HCHs}$}

Technical $\mathrm{HCH}$ was once widely used in China with a mixture of $65-70 \% \alpha-\mathrm{HCH}, 5-6 \% \beta-\mathrm{HCH}, 13 \% \gamma-\mathrm{HCH}$ and $6 \% \delta-\mathrm{HCH}$. Technical $\mathrm{HCH}$ was substituted by lindane in 1991 and approximately 3200 tons of lindane had been used until 2000, primarily concentrated in northern part of China (Hua and San, 1996). On average, the percentage of $\gamma-\mathrm{HCH}(36 \%)$ was comparable to those of $\beta-\mathrm{HCH}(31 \%)$ in the dustfall in Beijing. In comparison with those in particulate matter $(18 \%)$ collected in the same studied areas, the percentages in dustfall were much comparable to those $(\sim 54 \%)$ in the topsoils (Li et al., 2006), which indicated the reemission of $\mathrm{HCHs}$ from topsoil to atmosphere. $\beta-\mathrm{HCH}$ is more stable than other isomers and ratio of $\beta / \gamma-\mathrm{HCH}$ from 0.38 to 0.46 indicates a lack of current technical HCHs application in the studied area (Kim and Smith, 2001; Qiu et al., 2004). In addition, the ratio of $\alpha / \gamma-\mathrm{HCH}$ typically ranged from 4 to 7 for technical $\mathrm{HCH}$ mixture, while nearly zero for lindane (Iwata et al., 1995). Although there is photochemical isomerization of $\gamma-\mathrm{HCH}$ to $\alpha-\mathrm{HCH}$ in atmosphere, the action is slow compared with regional atmospheric transportation and will not change the ratio greatly in dustfall (Oehme and Manø, 1984; Poissant and Koprivnjak, 1996; Garmouma and Poissant, 2004). As shown in Fig. 4, the ratio of $\gamma / \alpha-\mathrm{HCH}(0.06-1.11$ with a median of 0.32 ) was less than 4 , which supports the conclusion that the sources of $\mathrm{HCHs}$ in dustfall of Beijing possibly come from both 

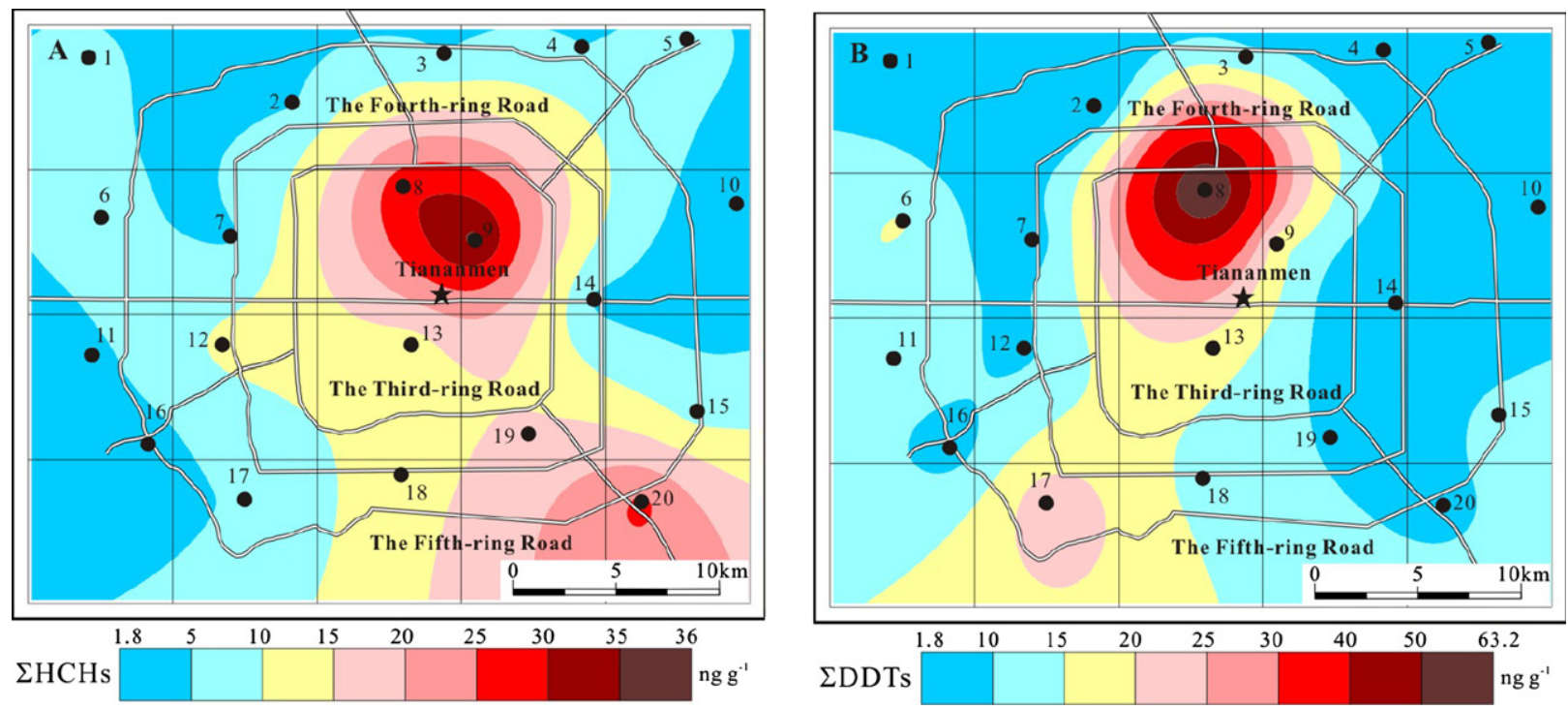

Fig. 3. Spatial distribution of $\sum \mathrm{HCHs}(\mathrm{A})$ and $\sum \mathrm{DDTs}(\mathrm{B})$ in dustfall in urban Beijing.

Table 1

Factor loading (varimax rotated) for oganochlorine compounds in dustfalls.

\begin{tabular}{lcrr}
\hline & PC1 & \multicolumn{1}{c}{ PC2 } & \multicolumn{1}{c}{ PC3 } \\
\hline$\alpha-\mathrm{HCH}$ & 0.89 & 0.00 & -0.24 \\
$\beta-\mathrm{HCH}$ & 0.93 & -0.22 & -0.17 \\
$\gamma-\mathrm{HCH}$ & 0.22 & 0.81 & 0.07 \\
$\delta$-HCH & 0.02 & 0.82 & -0.23 \\
$\mathrm{p}, \mathrm{p}^{\prime}$-DDT & 0.89 & -0.15 & -0.32 \\
, $\mathrm{p}^{\prime}$-DDT & 0.92 & -0.03 & 0.08 \\
$\mathrm{p}, \mathrm{p}^{\prime}$-DDD & 0.80 & 0.23 & 0.30 \\
p,p'-DDE & 0.38 & -0.03 & 0.89 \\
Proportion of total variance (\%) & 51.55 & 18.29 & 14.10 \\
\hline
\end{tabular}

historical usage of technical $\mathrm{HCH}$ and lindane. The relatively higher ratios were observed in samples out of the 4th Ring Road, indicating the effects of old sources of technical HCHs on the dustfalls. Generally, park and residential area were characterized with $\beta$ $\mathrm{HCH}$ as the major contributing compound and a high percentage of $\gamma-\mathrm{HCH}$ in farm dustfall indicated the possible agricultural application of lindane. One identified hotspot at site $8(\gamma / \alpha-\mathrm{HCH}$ of 1.11 and $\beta / \gamma-\mathrm{HCH}$ of 8.77 ) was polluted by the technical HCHs, while the other hotspot at site $9(\gamma / \alpha-\mathrm{HCH}$ of 0.06 and $\beta / \gamma-\mathrm{HCH}$ of 0.11 ) was possibly polluted by lindane.

\subsubsection{DDTs}

As shown in Fig. 4, the average percentages of individual compounds in dustfall were as follows: $\mathrm{p}, \mathrm{p}^{\prime}-\mathrm{DDT}>\mathrm{p}, \mathrm{p}^{\prime}-$ $\mathrm{DDE}>\mathrm{o}, \mathrm{p}^{\prime}-\mathrm{DDT}>\mathrm{p}, \mathrm{p}^{\prime}-\mathrm{DDD}$, which was different from the order of $\mathrm{p}, \mathrm{p}^{\prime}-\mathrm{DDE}>\mathrm{p}, \mathrm{p}^{\prime}-\mathrm{DDT}>\mathrm{p}, \mathrm{p}^{\prime}-\mathrm{DDD}>\mathrm{o}, \mathrm{p}^{\prime}$-DDT reported in topsoil in Beijing (Li et al., 2006).This suggested that the DDT compounds in dustfall was not merely from soil release, other sources possibly existed. Technical DDTs is typically composed of $77.1 \%$ p, $\mathrm{p}^{\prime}$-DDT, $14.9 \%$ o,p'-DDT, $4 \%$ p, $\mathrm{p}^{\prime}$-DDE and some other trace impurities. The relative amounts of DDT congeners were expressed as the fractional value of $\left(\mathrm{p}, \mathrm{p}^{\prime}\right.$-DDD $\left.+\mathrm{p}, \mathrm{p}^{\prime}-\mathrm{DDE}\right) / \mathrm{p}, \mathrm{p}^{\prime}$-DDT and the ratios are shown in Fig. 4. This ratio $>1$ is normally expected for aged mixtures in the environment and $<1$ indicates the relatively recent exposure to parent DDT (Jaga and Dharmani 2003). In this study, the ratio varied from 0.09 to 6.54 with a median of 0.69 . Nearly half of dustfall samples (sites 1, 2, 3, 4, 5, 7, 13, 14 and 16) contained more DDE and DDD than DDT, which indicated that the levels
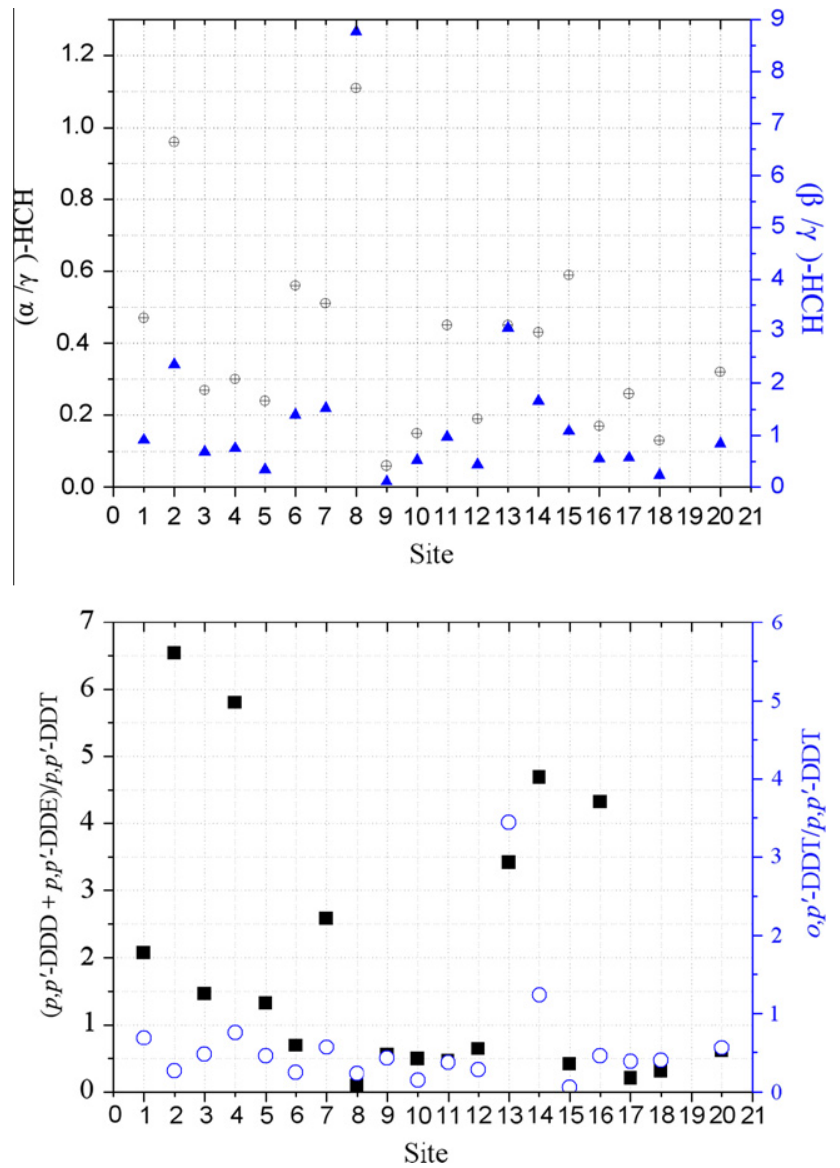

Fig. 4. Characterized ratio of HCHs and DDTs in dustfall in urban Beijing.

and proportions of DDTs in those suburban areas are affected by both old sources. While other sites, including the hotspots of sites 8 and 9 , showed that p,p'-DDT had a large percentage of over $50 \%$, indicating current application of DDT or input of dicofol since it contains about 3.5-10.8\% DDT (Luo et al., 2000). In fact, the total input of dicofol was from 3 ton $\mathrm{a}^{-1}$ to 4 ton $\mathrm{a}^{-1}$ in 2000 in Beijing (Xu et al., 2005). 
A ratio of $\mathrm{o}, \mathrm{p}^{\prime}-\mathrm{DDT} / \mathrm{p}, \mathrm{p}^{\prime}$-DDT can be used to distinguish technical DDT from "dicofol-type DDT", which was reported to be $0.20-0.26$ in technical DDT and about 7.5 in dicofol product (Qiu et al., 2005). Due to the environmental processes such as evaporation and air-surface exchange, the ratios would change and these product ratios would result in a calculated of 0.74-0.96 for technical DDT and 28 for dicofol-type DDT, respectively, in the atmosphere (Kurt-karakus et al., 2006; Liu et al., 2009). As shown in Fig. 4, the ratio in dustfall varied from 0.06 to 3.44 with a median of 0.43 , which suggests that technical DDT still dominate in the atmosphere in Beijing dustfall although possible "dicofol-type DDTs" was observed in dustfalls from a park (site 13: 3.44 ) and one residential area (site of 14: 1.24). It can be estimated that the current DDT sources in dustfall was composed of $\sim 10 \%$ of dicofol-type DDTs, which was higher than the average level of $\sim 5 \%$ in Chinese cities (Liu et al., 2009).

\subsection{Prediction of soil burdens of HCHs and DDTs}

The bulk depositions fluxes $\left(F_{\mathrm{D}}, \mathrm{ng} \mathrm{h} \mathrm{h}^{-1} \mathrm{~m}^{-2}\right)$ are presented in Table 1 and were calculated by

$F_{\mathrm{D}}=C W / A$

where $C$ is concentration ( $\mathrm{ng} \mathrm{g}^{-1}$ ) of HCHs or DDTs in dustfall, $W$ $\left(\mathrm{g} \mathrm{h}^{-1}\right.$ ) is converted hourly dustfall dried weight according to total dustfall collected during 1 year, $A$ is the bucket mouth area $\left(\mathrm{m}^{2}\right)$.

As shown in Table 2 , the average deposition flux was $1.14 \times$ $10^{5} \mathrm{ng} \mathrm{h}^{-1} \mathrm{~m}^{-2}$ for HCHs and $1.47 \times 10^{5} \mathrm{ng} \mathrm{h}^{-1} \mathrm{~m}^{-2}$ for DDTs. Based on the unit area fluxes and the studied area of $784 \mathrm{~km}^{2}$, the annual atmospheric deposition flux in 2006 in Beijing urban soil was $783 \mathrm{~g}$ for $\mathrm{HCHs}$ and $1010 \mathrm{~g}$ for DDTs, respectively. The model estimated deposition flux of HCHs in Beijing was $37.72 \mathrm{~g}$ in 2005 (Cao et al., 2005), which was over 20 times lower than that in the present study. The differences between the modeling and experimental results may come from both fugacity model and experimental monitoring limitation such as the relatively small sampling site (Wu et al., 2005). Although there are some degree of uncertainties for all estimates of atmospheric deposition of HCHs and DDTs, the modeling calculations to some extent suggest the current input of OCPs in/nearby Beijing in 2006, which should be notable. The average concentrations of HCHs and DDTs in particulate matter collected in 2006 were significantly higher than those in 2002-2003, which further confirmed the increasing of atmospheric OCPs in 2006 (Xu et al., 2005; Wang et al., 2008).

The soil burdens of OCPs depend on the difference between input and output. Pesticides are delivered to the soil mainly by local usage, wastewater irrigation and atmospheric deposition.
However, in this study, the sampling areas were urban areas and the soil was not irrigated by wastewater. Therefore, atmospheric deposition is assumed as the only plausible source in this study. The dominant losses of OCPs from the soil in the studied area include soil-air volatilization, soil erosion, degradation, etc. The erosion and compounds degradation in soil are not considered in this study and then the changes of OCPs in per $\mathrm{m}^{2}$ surface soil $(0-$ $20 \mathrm{~cm}$ ) could be expressed by

$\Delta C=\Delta F / W=\left(F_{\mathrm{D}}-F_{\mathrm{V}}\right) / W$

where $\Delta C\left(\mathrm{ng} \mathrm{g}^{-1} \mathrm{~h}^{-1} \mathrm{~m}^{-2}\right)$ is the variation of soil burden for $\mathrm{HCHs}$ or DDTs $(\Delta C>0$ indicating net atmospheric deposition to the soil, while $\Delta C<0$ indicating net volatilization from the soil), $\Delta F$ $\left(\mathrm{ng} \mathrm{h}^{-1} \mathrm{~m}^{-2}\right.$ ) is the net flux which is the driving force for OCPs volatilization due to the difference in fugacities between soil and air, $W$ ( $\mathrm{g}$ ) is the weight of surface soil and is $300 \mathrm{~kg}$ for the surface soil $(20 \mathrm{~cm})$ assuming the solid density to be $1500 \mathrm{~kg} \mathrm{~m}^{-3}, F_{\mathrm{V}}$ $\left(\mathrm{ng} \mathrm{h}^{-1} \mathrm{~m}^{-2}\right)$ is the volatilization flux, and was calculated using the Mackay's fugacity model according to (Mackay, 1991; Kobližková et al., 2009)

$F_{\mathrm{V}}=10^{9} D_{\mathrm{V}} f_{\mathrm{s}} M$

where $M$ is the molecular weight of chemical, $D_{\mathrm{v}}$, representing a molar flux between the soil and air compartments, is the transfer coefficient $\left(\mathrm{mol} \mathrm{h}^{-1} \mathrm{~Pa}^{-1} \mathrm{~m}^{-2}\right.$ ) which is defined based on the three resistance model (Mackay, 1991). Fugacity in soil $\left(f_{\mathrm{s}}\right)$ was calculated from (Mackay, 1991; Harner et al., 2001)

$f_{\mathrm{s}}=C_{\mathrm{s}} H / 0.411 \varnothing_{\mathrm{om}} K_{\mathrm{ow}}$

where $C_{\mathrm{s}}$ as reported elsewhere (Li et al., 2006) is the concentration of the chemical in soil $\left(\mathrm{mol} \mathrm{m}^{-3}\right)$ and was listed in Table 1 in this study for easily understanding, $H$ is the Henry's law constant $\left(\mathrm{Pa} \mathrm{m}^{3} \mathrm{~mol}^{-1}\right), K_{\mathrm{ow}}$ is the dimensionless octanol-water partition coefficient, the fraction of soil organic matter $\emptyset_{\text {om }}$ was 0.03 in this study.

Averagely, the model volatilization flux of $\mathrm{HCHs}$ was $2.41 \mathrm{ng} \mathrm{h}^{-1} \mathrm{~m}^{-2}$ while that of DDTs was $0.07 \mathrm{ng} \mathrm{h}^{-1} \mathrm{~m}^{-2}$. Basing on the deposition fluxes in the present study $\left(1.14 \times 10^{5} \mathrm{ng} \mathrm{h}^{-1} \mathrm{~m}^{-2}\right.$ for $\mathrm{HCHs}$ and $1.47 \times 10^{5} \mathrm{ng} \mathrm{h}^{-1} \mathrm{~m}^{-2}$ for DDTs), the prediction of the soil burdens of $\mathrm{HCHs}$ and DDTs was carried out and were listed in Table 1. Thus, according to Eq. (2), $\Delta C>0$ indicates the dominant deposition contributions to the soil burdens in urban Beijing and the net flux was $0.38 \mathrm{ng} \mathrm{g}^{-1} \mathrm{~h}^{-1} \mathrm{~m}^{-2}$ for $\mathrm{HCHs}$ and $0.94 \mathrm{ng} \mathrm{g}^{-1} \mathrm{~h}^{-1} \mathrm{~m}^{-2}$ for DDTs.

Table 2

Deposition flux in dustfall and predicted volatilization flux in urban Beijing.

\begin{tabular}{|c|c|c|c|c|c|}
\hline & \multicolumn{4}{|c|}{ Flux $\left(\mathrm{ng} \mathrm{h}^{-1} \mathrm{~m}^{-2}\right)$} & \multirow[t]{3}{*}{ Soil burden $\left(\mathrm{ng} \mathrm{g}^{-1} \mathrm{~h}^{-1} \mathrm{~m}^{-2}\right)$} \\
\hline & \multicolumn{2}{|c|}{ Volatilization $^{\mathrm{a}}$} & \multicolumn{2}{|c|}{ Deposition $\left(\times 10^{5}\right)$} & \\
\hline & Range & Mean $\pm \mathrm{SD}^{\mathrm{c}}$ & Range & Mean \pm SD & \\
\hline$\alpha-\mathrm{HCH}$ & $\mathrm{nd}^{\mathrm{b}}-0.79$ & $0.18 \pm 0.08$ & $0.02-0.32$ & $0.10 \pm 0.07$ & 0.03 \\
\hline$\beta-\mathrm{HCH}$ & $0.06-7.76$ & $0.87 \pm 0.45$ & $0.06-2.54$ & $0.35 \pm 0.06$ & 0.12 \\
\hline$\gamma-\mathrm{HCH}$ & nd-2.90 & $0.44 \pm 0.32$ & $0.08-2.48$ & $0.38 \pm 0.54$ & 0.13 \\
\hline$\delta-\mathrm{HCH}$ & nd-6.10 & $0.92 \pm 0.21$ & $0.02-2.25$ & $0.30 \pm 0.55$ & 0.1 \\
\hline$\sum \mathrm{HCHs}$ & $0.06-17.44$ & $2.41 \pm 0.68$ & $0.20-4.06$ & $1.14 \pm 1.07$ & 0.38 \\
\hline $\mathrm{p}, \mathrm{p}^{\prime}-\mathrm{DDT}$ & nd-2.01 & $0.05 \pm 0.21$ & $0.03-5.40$ & $0.78 \pm 1.20$ & 0.26 \\
\hline$o, p^{\prime}-D D T$ & l & 1 & $0.01-1.25$ & $0.28 \pm 0.33$ & 0.09 \\
\hline $\mathrm{p}, \mathrm{p}^{\prime}-\mathrm{DDD}$ & nd-0.18 & $0.01 \pm 0.12$ & $0.01-0.11$ & $0.05 \pm 0.03$ & 0.09 \\
\hline $\mathrm{p}, \mathrm{p}^{\prime}-\mathrm{DDE}$ & nd-0.30 & $0.01 \pm 0.26$ & $0.11-0.79$ & $0.36 \pm 0.17$ & 0.12 \\
\hline$\sum D D T s$ & nd-0.06 & $0.07 \pm 0.42$ & $0.19-7.17$ & $1.47 \pm 1.53$ & 0.94 \\
\hline
\end{tabular}

\footnotetext{
a Data from model prediction.

b At or below the detection of limits.

c Standard deviation.
} 


\section{Conclusions}

Despite restrictions on the usage of HCHs and DDTs, these pesticides are still prevalent in urban dustfall in Beijing. The possible application of lindane and dicofol in Beijing should be notable. The polluted dustfall will eventually deposit on the surface soil, enter the food web, and impact on the human health. The surface soil will continue to be a sink of atmospheric HCHs and DDTs for a long time in Beijing, China. As one of 173 parties of the Stockholm Convention pledging to take sound management of the OCPs inventories, the identification of several hotspots would be very helpful for China to cut the application of HCHs and DDTs in Beijing and nearby areas.

\section{Acknowledgments}

The work was supported by National Natural Scientific Foundation of China (40673066). We appreciate the valuable suggestions from the anonymous referees.

\section{References}

Cao, H.Y., Liang, T., Tao, S., 2005. Simulating the transfer and fate of hexaclorocyclohexane in recent 50 years in Beijing, China. Sci. China D Earth Sci. 48, 2203-2213.

Derbyshire, E., Meng, X., Kemp, R.A., 1998. Provenance, transport and characteristics of modern aeolian dust in western Gansu Province, China, and interpretation of the quaternary loess record. J. Arid Environ. 39, 497-516.

Garmouma, M., Poissant, L., 2004. Occurrence, temperature and seasonal trends of alpha and gamma-HCH in air (Quebec, Canada). Atmos. Environ. 38, 369-382.

Harner, T., Bidleman, T.F., Jantunen, L.M.M., Mackay, D., 2001. Soil-air exchange model of persistent pesticides in the United States cotton belt. Environ. Toxicol. Chem. 20, 1612-1621.

Hua, X.M., San, Z.J., 1996. The production and application of pesticides and factor analysis for their pollution in environment in China. Adv. Environ. Sci. Technol. 4, 33-45.

Iwata, H., Tanable, S., Ueda, K., Tatsukawa, R., 1995. Persistent organochlorine residues in air, water, sediment, and soils from the Lake Baikal region, Russia. Environ. Sci. Technol. 29, 792-801.

Jaga, K., Dharmani, C., 2003. Global surveillance of DDT and DDE levels in human tissues. Int. J. Occup. Environ. Health 16, 7-20.

Kim, J.H., Smith, A., 2001. Distribution of organochlorine pesticides in soils from South Korea. Chemosphere 43, 137-140.

Kobližková, M., Růžičková, P., Čupr, P., Komprda, J., Holoubek, I., Klánová, J., 2009. Soil burdens of persistent organic pollutants: their levels, fate, and risks. Part IV. Quantification of volatilization fluxes of organochlorine pesticides and polychlorinated biphenyls from contaminated soil surfaces. Environ. Sci. Technol. 43, 3588-3595.

Kurt-karakus, P.B., Bidleman, T.F., Staebler, R.M., Jones, K.C., 2006. Measurement of DDT Fluxes from a historically treated agricultural soil in Canada. Environ. Sci. Technol. 40, 4578-4585.

Li, X., Zhu, Y., Liu, X., Fu, S., Xu, X., Cheng, H., 2006. Distribution of HCHs and DDTs in soils from Beijing city, China. Arch. Environ. Contam. Toxicol. 51, 329-336.

Li, Y.F., Cai, D.J., Singh, A., 1998. Hexachlorocyclohexane use trends in China and their impact on the environment. Arch. Environ. Contam. Toxicol. 35, 688-697.
Li, Y.F., Cai, D.G., Shan, Z.J., Zhu, Z.L., 2001. Gridded usage inventories of technical hexachlorocyclohexane and lindane for China with $1 / 6^{\circ}$ latitude by $1 / 4^{\circ}$ longitude resolution. Arch. Environ. Contam. Toxicol. 41, 261-266.

Li, Y., Zhang, Q., Ji, D., Wang, T., Wang, Y., Wang, P., Ding, L., Jiang, G., 2009. Levels and vertical distributions of PCBs, PBDEs, and OCPs in the atmospheric boundary layer: observation from the Beijing 325-m meteorological tower. Environ. Sci. Technol. 43, 1030-1035.

Liu, X., Zhang, G., Li, J., Yu, L.L., Xu, Y., Li, X.D., Kobara, Y., Jones, K.C., 2009. Seasonal patterns and current sources of DDTs, chlordanes, hexachlorobenzene, and endosulfan in the atmosphere of 37 Chinese cities. Environ. Sci. Technol. 43, 1316-1321.

Luo, P., Liu, Y.M., Fu, S.Q., 2000. Analysis and evaluation of the quality of the green tea and the BHC, DDT, lead pollution in green tea in southwest China. J. Agric. Sci. 13, 110-114 (in Chinese).

Ma, L.L., Chu, S.G., Wang, X.T., Cheng, H.X., Liu, X.F., 2005. Polycyclic aromatic hydrocarbons in the surface Soil from outskirts of Beijing. Chemosphere 58, 1355-1363.

MCI (Ministry of Chemical Industry), 1992. On Implementation of the Notification from the Office of the State Department on Management of Pesticides and Animal Medicines, vol. 77, Beijing.

Mackay, D. 1991. Multimedia Environmental Models: The Fugacity Approach; Lewis, Chelsea, Boca Raton FL.

Oehme, M., Manø, S., 1984. The long-range transport of organic pollutants to the Arctic. Fresenius. J. Anal. Chem. 319, 141-146.

Poissant, L., Koprivnjak, J.F., 1996. Fate and atmospheric concentrations of $\alpha$ - and $\gamma$ hexachlorocyclohexane in Oúebec, Canada. Environ. Sci. Technol. 30, 845-851.

Pozo, K., Harner, T., Wania, F., Muir, D.C.G., Jones, K.C., Barrie, L.A., 2006. Toward a global network for persistent organic pollutants in air: results from the GAPS study. Environ. Sci. Technol. 40, 4867-4873.

Qiu, X., Zhu, T., Li, J., Pan, H., Li, Q., Miao, G., Gong, J., 2004. Organochlorine pesticides in the air around the Taihu Lake, China. Environ. Sci. Technol. 38, 1368-1374.

Qiu, X., Zhu, T., Yao, B., Hu, J., Hu, S., 2005. Contribution of dicofol to the current DDT pollution in China. Environ. Sci. Technol. 39, 4385-4390.

Roosens, L., Abdallah, M.A., Harrad, S., Neels, H., Covaci, A., 2010. Current exposure to persistent polychlorinated biphenyls (PCBs) and dichlorodiphenyldichloroethylene ( $\left.\mathrm{p}, \mathrm{p}^{\prime}-\mathrm{DDE}\right)$ of Belgian students from food and dust. Environ. Sci. Technol. 44, 2870-2875.

Tao, S., Liu, W.X., Li, X.Q., Zhou, D.X., Li, X., Yang, Y.F., Yue, D.P., Coveney, R.M., 2009. Organochlorine pesticide residuals in chickens and eggs at a poultry farm in Beijing, China. Environ. Pollut. 157, 497-502.

Wang, X.F., Li, X.H., Cheng, H.X., Xu, X.B., Zhuang, G.M., Zhao, C.D., 2008. Organochlorine pesticides in particulate matter of Beijing, China. J. Hazard. mater. $155,350-357$.

Wong, F., Alegria, H.A., Jantunen, L.M., Bidleman, T.F., Salvador-Figueroa, M., Gerardo Gold-Bouchot, G., Ceja-Moreno, V., Waliszewski, S.M., Infanzon, R., 2008. Organochlorine pesticides in soils and air of southern Mexico: chemical profiles and potential for soil emissions. Atmos. Environ. 42, 7737-7745.

Wu, S.P., Tao, S., Lan, T., Li, B.G., Cao, J., Liu, W.X., Liu, Y., Meng, B.J., 2005. Hexachlorocyclohexane and dichlorodiphenyltrichloroethane residues in the dustfall of Tianjin, China. J. Environ. Sci. Health, Part A Environ. Sci. 40, 17151730.

Xu, D.D., Zhong, W.K., Deng, L.L., Chai, Z.F., Mao, X.Y., 2004. Regional distribution of organo-chlorinated pesticides in pine needles and its indication for socioeconomic development. Chemosphere 54, 743-752.

Xu, D.D., Mo, D., Song, Y., Chai, Z.F., Zhuang, G.S., 2005. Concentration characteristics of extractable organohalogens in PM2.5 and PM10 in Beijing, China. Atmos. Environ. 39, 4119-4128.

Xu, G.F., Ma, L.L., Xu, D.D., Li, S.Z., Yao, D.X., Shi, W.Q., 2009. Characteristics and sources of dissolved organochlorine pesticides in the rainwater in Beijing. China Environ. Sci. 29, 1153-1157 (in Chinese).

Zhu, Y., Liu, H., Xi, Z., Cheng, H., Xu, X., 2005. Organochlorine pesticides (DDTs and $\mathrm{HCHs}$ ) in soils from the outskirts of Beijing, China. Chemosphere 60, 770778 